\title{
From System-of-Systems to Meta-Systems: Ambiguities and Challenges
}

\author{
G. Reza Djavanshir ${ }^{1}$, Ali Alavizadeh ${ }^{2}$ and M.J. Tarokh ${ }^{3}$ \\ ${ }^{1}$ Johns Hopkins University, \\ 2Indiana University-Purdue University Fort Wayne, \\ ${ }^{3}$ K.N. Toosi University of Technology, \\ $1,2 U S A$ \\ ${ }^{3}$ Iran
}

\section{Introduction}

While the term system-of-systems (SOS) is widespread and generally recognized within academia and industry, there is still confusion about its definition. For example, there are many different interpretations of system-of-systems (Sauser, and et at., 2009). A sample of different definitions is provided by Jamishidi (2005). So far, little research has been done to provide standard definitions of its characteristics. Many prominent researchers including Dagli, Kilicay-Ergin, (2009), Buede (2009), Keating (2009), Eisner (1997), and Djavanshir (2005) accept that systems-of-systems are meta-systems that exhibit meta-systemic behaviors. The meta-system provides the structural mechanism that integrates a system-ofsystems as a whole ((Beer, 1979,1981) and Keating (2009)) and prevents it from falling into chaos. This is accomplished by a meta-system's governance system. Therefore, a metasystem is a system-of-systems that has an additional characteristic, called a governance system, which integrates the system-of-systems' components, and provides balanced operations among them in order to achieve a common mission and strategy. According to our studies and understanding (Beer 1979, 1981, Esiner (1997), Keating (2009), Dagli and Kilicay-Ergin (2009), Buede (2009), and Djavanshir, et. al., 2009), if any system-of-systems possesses two properties, namely, (1) evolutionary process between the system-of-systems and its component enterprise systems and (2) passion of integrated centralized governance system, the system-of-systems is called a meta-system. In this chapter we will call a systemof-systems with these two characteristics a meta-system. Furthermore, the concept of metasystem provides powerful means to a better understanding of the so-called system-ofsystems' nature, characteristics (Esiner, 1997, Djavanshir, and et. al., 2009, Klir, 1985, Kawakek, 2002, and Buede, 2009), behaviors (Keating, 2009), and finally, its structure (Dagli, Kilicay, Ergin, 2009). Furthermore, accepting the fact that meta-systems are the extended version of meta-systems with these properties, enables researchers to apply well-researched, standardized and accepted definitions, behaviors, and characteristics of meta-systems in studying, understanding, designing, and deploying the so-called systems-of-systems.

Therefore, a meta-system is an extended and robust version of a system-of-systems. In this book chapter we attempt to define it. 
A meta-system is a complex system-of-systems with a centralized governance structure that coordinates the operational behaviors of the component systems and provides the strategic framework that guides the component systems to the achievement of their shared emergent mission. The component systems of meta-systems are composed of technological artifacts and informational, organizational, managerial, and human elements; these heterogeneous elements are integrated together to create emergent capabilities and capacities for achieving their shared function(s). Meta-systems possess a governance system that controls, which are described as follows:

1. Infrastructure system can include electric power grids, roads, airport facilities, supply chains, tools, assembly lines, technological artifacts, and all other resources.

2. Communications system contains various multimedia networks such as, voice, data, and video communication networks; the internet and intranet; and learning channels that provide knowledge gain and accumulations that are essential to both metasystems' operations and its effective functioning within uncertain and changing environments. The communications system also provides error detections, feedback, fault isolations, and correction mechanisms by continuously reexamining the adequacy of its design (Keating, 2009). A communication exchange between a meta-system's components not only make achieving the function possible, but they also enable the components to evolve and adapt to each other. Communications system also help the emergence of a self-organizing structure in chaotic situations (Keating, 2009).

3. Governance system is composed of people, processes, organizations, and products that provide interface protocols for those involved in the design and operation of metasystems. The governance system enables the meta-system to provide smooth operations of components. Also, it control the the overall operation of achieving the meta-systems' function. However, it does not manage the daily operations of the component systems. That is, flexibilities are provided to all components in choosing the tactical executions of their functions. A meta-system's ultimate role is to provide a seamless design of its three main system-components, in order to create a shared capability to achieve the meta-system's function.

Heterogeneous elements such as, people, institutions, organizations, information, and technologies create various systems that make up the components of a meta-system. In other words, the components of a meta-system are systems whose elements come from three integrated networks. Therefore, component systems are composed of heterogeneous elements of technologies, tools, processes, people, organizations, information and communications networks, and resources.

This chapter will be composed of five sections: Section 1 will provide an introduction, Section 2 will discuss the characteristics of meta-systems, and Section 3 will provide the description of, and the rational for, a centralized governance mechanism. The solicited opinions of a survey of experts and practitioners' views on systems-of-systems and metasystems will be described in Section 4. Finally, Section 5 will provide a conclusion and recommendations for future research.

\section{Characteristics of meta-systems}

Building on the definitions provided by Sage, Cuppon; Keating(2009), Dagli and KilicayErgin (2009), Eisner (1997), and (Djavanshir, et al., 2007), we came up with the following critical characteristics: 


\subsection{Different elements}

Meta-systems are composed of systems whose elements can be: technological artifacts, information, and communication channels; energy generators and transmission systems; or organizations, people, and processes.

\subsection{Constrained Autarky of distributed enterprise systems}

According to Webster's dictionary, Autarky means self-sufficiency and managerial independence. Autarky of distributed enterprise (component) systems in the context of meta-systems means that the component systems are separate and autonomous systems, yet they are integrated and combined together by the meta-systems, and they exist for the purpose of serving the shared mission of the meta-system (Luhmann, 2003 and Kauffman, 1994). While they have operational and managerial tasks (Wells and Sage, 2009 and Eisner and Marciniak, 1991), there are still resources, financial, and capital flows between the distributed enterprise systems and the governance system of the meta-systems. Constrained autarky of distributed systems implies that these systems do not possess full, independence from the meta-systems that govern them by way of the design of these systems, which is to ensure the effective accomplishment of their shared function and to prevent the operations of the meta-systems from falling into chaos. Moreover, constrained autarky means that the variable autonomies of distributed systems range from full autonomy to full dependency. In other words, the autonomy of each distributed system is a function of variables such as, skills and talents the criticality distributed systems' operations to the overall mission, operation of a meta-system, and the amount of investments spent on the systems. For example, distributed systems do not have decisions that are critical to the survival or failure of the meta-systems, they cannot make decisions, nor can a distributed system decide to ignore the decisions that are accepted by the entire meta-system. However, depending on the mission, distributed systems are either autonomous in making small decisions or they are autonomous in managing their programs and running their daily operations in terms of scheduling, maintenance, and acquisitions.

\subsection{Topological dispersion of distributed systems}

Component systems can be dispersed in large geographic areas. These systems collaborate with each other and are linked to the governance mechanism through constant communication and the flow of resources, information, and strategic decisions to fulfill the meta-system's overall mission.

\subsection{Governance system}

Meta-systems possess a governance system that provides an overall control and oversees the system's overall function and operations. The role of a governance system is to control and manage the component systems' behavior.

Governance structure also articulate the functions and overall mission of the meta-systems. Additionally, it facilitates the teamwork and effcient processes throughout the entire system. In order to respond to the changing environment and to effectively achieve its goals and 
missions, a meta-system must have a control system that manages the changes in its overall functional behavior. Strategic control is not the detailed change strategy, but rather it articulates the meta-system's mission and functions and provides a general description of how the system can accomplish its stated function. Strategic control is based on the assumption that the detailed knowledge about a change or design strategy is part of the change or design process. Therefore, it provides a flexible framework for implementation tactics.
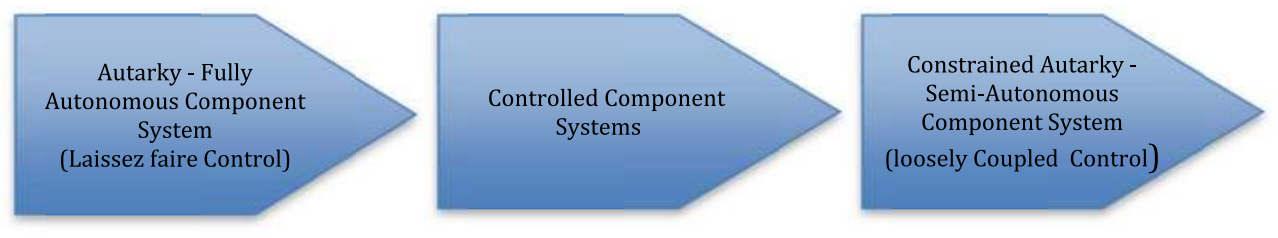

Fig. 1. Continuum of Constrained Autarky (Variant-Autonomy) of Component Systems

\subsection{Evolutionary process}

The environment in which meta-systems are located is always uncertain and evolving, therefore, the requirements specification of meta-systems is always evolving and changing. The component systems are created for and integrated by means of the meta-system, while the meta-system itself exists and is created by means of its interacting component systems. The process of the creation of a meta-system and its component systems, results in selforganization of the entire meta-system.

Meta-systems are developed through an evolutionary process, where the components of the meta-system are modified in response to the changing environment. As the environment changes, meta--systems' and configuration change as well. Therefore, a meta-system's, configuration, and final design are always evolving (Well and Sage 2009). In other words, as the environment evolves, the meta-system redesigns itself to adapt and respond to new conditions in a evolutionary manner. Evolution means the environment changes, the metasystem's entities adapt to their environment over time.

\subsection{Emergence property}

There are two related forms of emergence or type II properties (Gharajedaghi, 1999) in meta-systems. The first type is intentional and by design, where new capabilities, behaviors, and properties emerge from the process of structural interactions among the meta-system's components. The second type is the unintended consequence of not knowing about the emergence in advance (Keating, 2009). This unpredictable behavior comes from the process of the interactions of the meta-system within an uncertain and unpredictable environment. 
With respect to the changing environment and the emergence of unintended consequences, the detailed design and specifications of a meta-system should not be specified in advance of its operation. Rather, the knowledge and information about the meta-system's design should be part of its design, operations, and implementation process. In other words, the system design should be based on the law of minimum specifications (Keating, 2009). Otherwise, the detailed specifications and design increase the system's complexity, which creates a structural sclerosis that restricts the meta-system's agility and its responsiveness to the evolving uncertain environment and emergent unintended consequences. Furthermore, it restricts the meta-system's capacity to self-organize and self-produce based on the contextual information. Therefore, meta-systems should be designed with minimum specifications.

\section{The governance system}

Governance controls the collective actions overall function of the component systems in the meta-system. As shown in Figure 2, the governance structure is integrated but centralized entity in direct contact with all component systems of the meta-system that exchanges information. In meta-systems, centralized governance system mechanism is needed. It does not manage component systems in terms of providing control. However, it formulates the overall design of the meta-system. It provides control, and coordination of efforts to achieve the mission. and to prevent the system from falling into chaos.

Meta-systems are complex constructs. Their complexities, coupled with the uncertainty of the environment. DeRosa (2001) emphasizes the need for a governance mechanism in largescale enterprise systems that are composed of human, informational, organizational, and technological elements. The governance mechanism is used to:

1. Define the goal that should be achieved through the meta-system, as well as the capabilities expected from component systems, in order to achieve the desired outcome. Component systems should collectively provide the expected functions to succeed in achieving their mission.

2. Facilitate the flow of information, to facilitate operations

3. Facilitate the creation of a environment that maintains the control of meta-systems during internal and external changes and turbulence (Keating, 2009). Balance and the maintenance of balance, is achieved through adjustments to changes, shifts, and disturbances (Keating, 2009).

4. Formulate the meta-systems' governance functions to avoid chaos. In changing environments, meta-systems' design are always evolving, and their development and deployments evolve with the changes in the environment and in requirements. Therefore, meta-systems' and integration proceed according to uniform standardized design integrations model. The design models and the overall fitness rules are shaped by the efforts of the meta-systems' governance system and its component systems. The governance system creates rules and structures which will in turn aid in the achievement of the meta-system's functions. Even if the individual component enterprises and their managers pursue their own self-interests, the Governance system should create an environment for the functioning of all members of the meta-system (McCarter and White, 2009). 


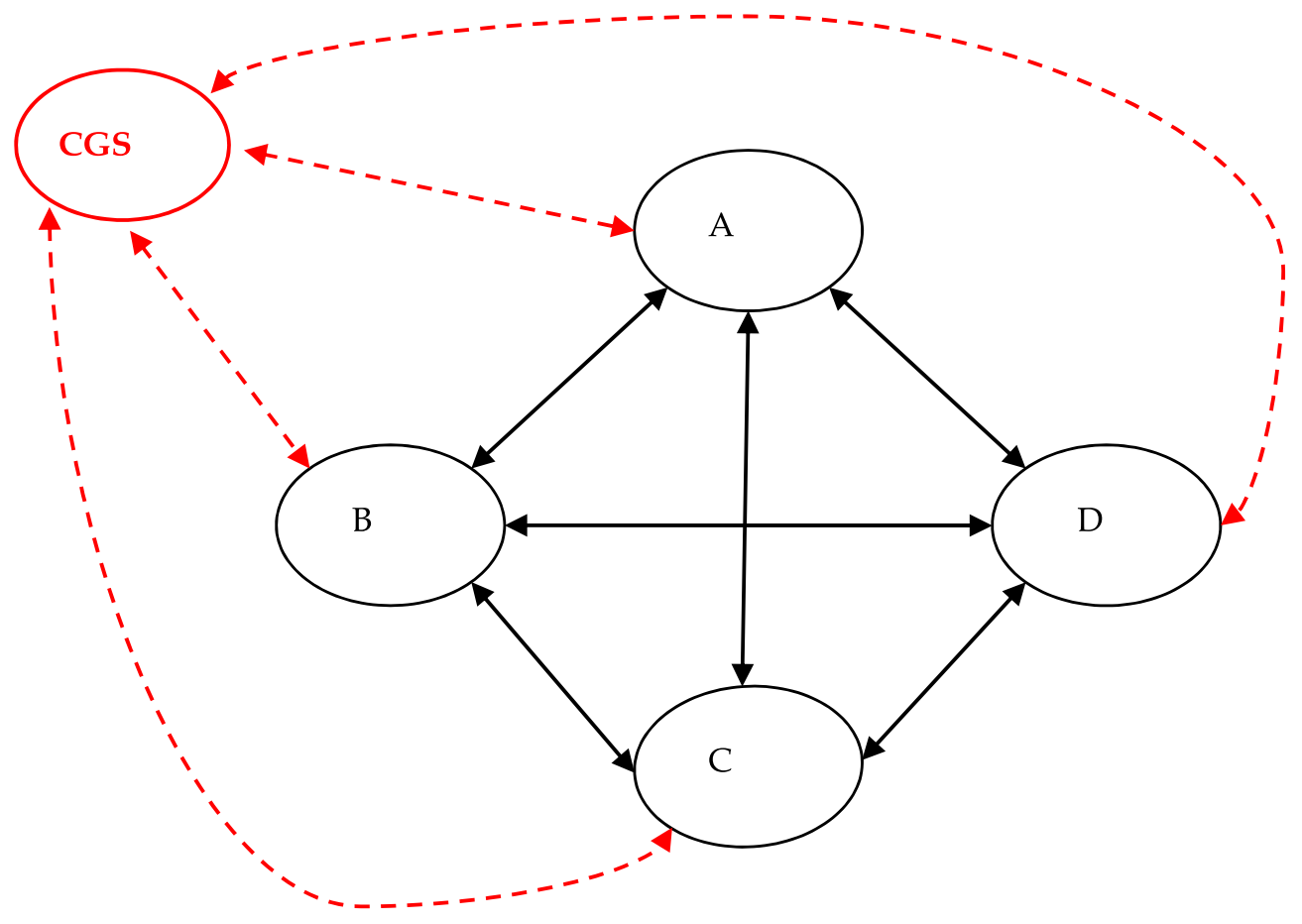

Fig. 2. Illustration of a Governance Structure 


\section{Experts' views on meta-systems}

To provide a comprehensive view of system-of-systems, we also conducted literature research with experts in order to solicit experts' opinions of system-of-systems and metasystems. A more in-depth reasoning behind the definitions was needed to establish a true understanding of what a system-of-systems is, the characteristics that define it, as well as the differentiation between a system-of-systems and a meta-system. This section explores the results of selected surveys. It is important to note that, given the short timeframe within which this research was conducted, only literature search was used. Therefore, the obtained results are certainly not enough to provide a "representative sample." The majority of literature articles are, however, were written by subject matter experts in the field. The research results were gathered from average system-of-systems experts with special practical knowledge of systems-of-systems; in other words, not academic subject matter experts, but also those with professional perspectives from the field. The information that was obtained is described in this section, but the authors welcome additional researchers to continue this effort. The results obtained to date are quite intriguing, and rather contradictory.

To provide a focused and coherent structure to our interviews, two questions were asked and searched in some instances where time or interest did not permit the respondent to complete the entire questionnaire. It was necessary to shorten the scope of the questions for some respondents and us in order to obtain timely responses. In one instance, the response was limited to an even smaller subset. The questions were as follows:

1. What is your definition of a system-of-systems?

2. What is your definition of a meta-system?

Some definitions (Djavanshir, et, al., 2007) include central control of the overall system and use the term meta-system to describe a system-of-systems while others do not recognize the concept of centralized control (Maier, 1998). Subject matter experts in the field express different opinions on SoS control ranging the gamut, including control as a necessity (Djavanshir, et, al., 2007), control as an impossibility (Maier, 1998) and control as a possibility depending on SoS hierarchy. We believe that the concept of centralized control does hold merit as it pertains to the systems environment because a centralized control structure is required to maintain order of the system. Whether the term meta-system is synonymous with SoS, however, is a subject requiring additional research.

Experts believe that evolution of systems has led to the development of the system-ofsystems concept (Djavanshir, et. al., 2007) System-of-systems generally include various heterogeneous systems such as existing systems and new systems in some instances, to provide a particular functions or service. Thus, the challenges and complexities involved in designing such systems have given birth to a new field of systems engineering known as SoSE or System-of-Systems Engineering. Researchers are continuously researching the methodologies and processes currently in practice for SoSE. Two main groups are leading the charge: National Center for System-of-Systems Engineering (NCSOSE) and the Systemof-Systems Engineering Center of Excellence (SoSECE). These groups are at the forefront of SoSE and have taken leadership roles in standardizing the discipline. Nevertheless, this new field has brought on some challenges, especially regarding its design. Due to the complex nature of SoS, emergent factors, and the fact that the newly designed system may be a 
mixture of different existing and new systems that are geographically located, the SoSE design team must be diligent and consider all factors that may affect overall performance of the system.

One thing is clear: the future opportunities of system-of-systems applications such as, in artificial intelligence, are limitless, and are bound to change the world. Thus, SoS applications will become more common, requiring greater understanding and standardization of SoSE design principles to address the demands of the emergent properties of a SoS.

The future of system-of-systems appears endless in this ever-growing age of technology. This concept of large-scale integration can be used to satisfy numerous goals for future projects. This new area will probably be beneficial across many nations, governments, and multinational corporations. It is becoming more widely accepted that system-of-systems will present a real opportunity to future executives of government agencies and industrial companies. New computing paradigms such as Artificial Intelligence (AI) will continue incorporating fuzzy logic into systems-of-systems and will push into mainstream efforts.

There are numerous requirements that could necessitate the advancement and desire for future applications of meta-systems. Since more companies are multinational, the sharing of information between independent systems could be the key to success for the company as a whole. For example, multinational financial institutions such as banks and investment firms usually operate independently, but the financial markets globally are so closely linked, they must continually come up with ways to better integrate their systems. The top level leadership must ensure they have a control system which allows information to flow smoothly both ways.

The transportation industry, for example, could significantly benefit from a new and improved new meta-system in the future. All independent transportation systems, including air travel, maritime, trains, and buses, could be individual complex components of a larger Department of Transportation meta-systems. The recent trends towards modular systems development would greatly enhance this capability. The information from this system would be critical in natural disasters and national emergencies. The benefits are also weighed down by drawbacks. Even though these systems are independent from each other, any negative effect on one could dramatically affect the others. If there were, say, grounded aircraft, this could increase the traffic for trains and buses dramatically.

The opportunities seem endless but the near term focus would seem to be in the Department of Defense (DOD), large government agencies and multination corporations. Projects could include such things as future combat systems for the DOD, improvements to the FAA's aviation program, NASA's space and satellite program, Global weather forecasting, and sharing of information and resources between independent branches of large corporations. This could also prove beneficial to large-scale projects for the federal governments.

The experts and practitioners' responses to these questions were as follows:

Andrew Sage: His definition of a system-of-systems, and reiterated in his communications with one of the authors, does not include any mention of control of the overall system. He also uses the term "Systems Family." He does not, however, use the term meta-system. His understanding of a meta-system as it is defined by Renee Stevens at MITRE, is that it is 
essentially the same as a system-of-system (SOS). Sage believes that there needs to be a way to govern and manage a SOS, but that diverges into the arena of Federation of Systems efforts. He has not considered the inclusion of a centralized transition control strategy in a SOS.

Maier: He does not recognize the term meta-system, since it is not standardized. His definition conflicts with the concept of control needs in a system-of-systems, stating, "To me, SOS and lack of central control are synonymous. I don't know of any single best practice for stability." In general, "stability" is not a well-formed concept for complex things. There is technical stability, which is how a control theorist would describe stability. He delves deeper into these issues in his papers, "Architecting Principles for Systems-of-Systems" and "On Architecting and Intelligent Transport Systems." This view is quite interesting.

Jamshidi: He defines a system-of-systems as, "a super-system consisting of an integration of an emerging set of heterogeneous systems required to work together for a common purpose, i.e. increased robustness, performance, cost, etc." He believes that meta-systems are more general than systems-of-systems, though some meta-systems may also be systems-ofsystems, as stated below. Meta-systems have several definitions that link the concepts of systems-of-systems with those of meta-systems. A vague indication, suggested by A.M.Gadomski is, "one may assume that meta-systems are systems composed of the common properties of a large class of systems, but not related to its particular domaindependent properties." According to V. Turchin and C. Joslyn, this "natural" definition is not sufficient for the Theory of Meta-system Transition; it is also not congruent with the definition of system-of-systems in Systems Theory. Regarding control, Jamshidi agrees that centralized control of a SOS may be possible, depending on its architecture. He believes a hierarchical architecture would lend itself to such a paradigm. Jamshidi also agrees that the requirements management of a SOS is daunting, "Modeling of SOS is a very challenging task, if not impossible. However, it is possible to utilize a peer-to-peer approach for data exchange between systems of a SOS, using tools like XML language and discrete-event simulation to actually simulate a SOS without the benefit of a mathematical model. Currently, we are looking at national Instruments' LabView as an alternative approach to simulating SOS."

Crossley: William Crossley's definition is as follows of SOS, "A system-of-systems is any collection of systems, each of which is capable of its operation, that must interact to achieve their purposes or gain value none can fully realize alone. Like a single system, a SOS is a collection of components interacting to fulfill one or more functions. But the constituent systems of a SOS can perform useful functions alone - something components of a single system cannot - and removal of any system from a SOS need not prevent its continued operation."

His thoughts regarding SOS control are that the level of control over a system-of-systems helps in its classification. One of the ideas we have been developing is that the amount of classifications exerted over the component systems is a way to classify a system-of-systems. A system-of-systems, like a battle group or an airline (two examples we have used), could have a fairly "strong" controlling authority. Other systems-of-systems may have very little centralized control; other researchers have attempted to describe the internet/worldwide web as an "uncontrolled" system-of-systems. Mr. Crossley has been researching methods of identifying SOS Engineering problems. He is "looking at how to describe "design" problems in a system-of-systems context using an optimization (or mathematical programming) 
problem statement. This may only work for a class of SOS problems." This research is very much needed. A scientific or methodical approach to handling SOS Engineering is needed in every aspect, including: the identification of the problem, analysis, requirements management, etc. The tools and methods in place for handling systems engineering are not sufficient for the additional complications of SoSE.

Industry Practitioners: The industry practitioner respondents recognized the terms systemof-systems, meta-systems, and enterprise systems, but were not sure of the differences between them. One suggested that "system-of-systems is a term that has been recently coined, in the last few years, and refers to net-centric, distributed systems spanning many types of domains." In general, the terms were not differentiated well. At least one believed that the progress of systems-of-systems would be hindered in the future, "The drawbacks are that we do not have a good handle on the definition and implementation of System-of-Systems today. The fact that we are dealing with ever-increasing interface standards and poorly engineered COTS solutions threaten to limit their use."

The surveys confirm the author's beliefs that SOS engineering is in its infancy. Some systems engineers have cursory knowledge of the problem, while others treat SOS problems the same as they treat any other systems problems. It will take time (and standardization) of this industry before the information trickles-down and reaches the field. Standardization will lead to better processes and more efficient methods.

\section{Conclusion and recommendations}

In this book chapter we provided a definition of a meta-system and its main characteristics. A meta-system provides the structure, processes, and governance mechanism that integrate and synchronize the operational capabilities of SOS. Meta-systems are composed of heterogeneous component systems consisting of: people, technological artifacts, infrastructure, resources, support systems, information, organizations, and regulative, normative, and cultural cognitive institutions. Meta-systems have uncertain environment changes (sometimes with high velocity), incomplete and variable specifications, and an elastic boundary.

There are also symbiotic and commensalist relationships between a meta-system and its component systems. Symbiotic and commensalist relationships mean that intertwined, interdependent or partially interdependent entities help each other (symbiotic relationship) and use each other (commensalist relationship) respectively (Eisenhardt and Galunic, 2000). Furthermore, meta-systems and their component systems not only co-create each other, but they also co-adapt, collaborate, and co-evolve.

We also emphasized on the importance of a loosely centralized governance mechanism that governs (not manages or rigidly controls) the overall operation of meta-systems and prevents meta-systems from falling into chaos. It also balances the opposing tendencies within metasystems. Governance mechanisms provide balance among the opposing tendencies, guidance and policies that facilitate cooperative behaviors, and guidance and policies that further the emergence of self-organizing behavior out of complex and chaotic situations.

In this book chapter, we also provided a survey of experts and practitioners' views on system-of-systems, meta-systems and their differences. 
For future research, it is recommended that the concepts of governance mechanism and various degrees of the autonomies of its component systems be examined and their governances also be studied.

Additionally, the concept of the complex system (self-organizing, where a whole exists for and is created by its parts and vice-versa) can further examine meta-systems.

\section{Acknowledgement}

The authors would like to thank Ms. Katherine L. Hudak of Johns Hopkins' Carey Business School for her insightful editorial work.

\section{References}

Beer, S. (1997). The Heart of Enterprise, John Wiley

Buede, D., M. (2009). The Engineering Design of Systems, 2nd Ed. John Wiley. Hoboken, N.J.

Dagli, D., H., and N., Kilicay-Ergin. (2009). "System of Systems Architecting." In System of Systems Engineering, Innovation for the 21 ${ }^{\text {st }}$ Century. Jamshidi, M., ed. Hoboken, N.J. John Wiley, pp. 77-100.

DeRosa, J., K. (2011). “Introduction.” In Enterprise Systems Engineering. Rebovich, G., Jr., and B.E. Whites, eds. Boca Raton, FL: CRC Press, pp. 1-30

Djavanshir, G.R., Khorramshahgol, R. and J. Novitzki. (2009). Critical Characteristics of Meta-systems: Toward Defining Metasystems Governance Characteristics. IEEE, ITPro. May/June Issue, pp. 31-34.

Eisner, H. (1997). Essentials of Project and Systems Engineering Management. NJ: John Wiley, p. 214.

Eisenhardt, K., and D. C., Galunic. (2000). Coevolving At Last a Way to Make Synergies Work. Harvard Business Review. January-February, pp. 83-101.

S. Kaufffman. (1995). At Home in The Universe. NYC. NY: Oxford University Press, pp. 274275.

Kawakek, P., and D.G., Wastell. (2002). "A Case Study Evaluation of the Use of the Viable System Model in Information Systems Development." In Information Systems Evaluation Management. Van Grembergen, W., ed. London, UK. IRM Press, pp. 1734.

Keating, C. (2009). "Emergence in System of Systems." In System of Systems Engineering, Innovation for the $21^{\text {st }}$ Century. Jamshidi,M., ed. Hoboken, N.J. John Wiley, pp. 169-217.

Keating, C. et al., (2003). “System of Systems Engineering,” Eng. Management J., vol. 15, no. 3, pp. 36-45.

Klir, G. (1985). Architecture of Systems Problem Solving, PlenumPress, p. 305.

Maier W.M. (1998). "Architecting Principles for System-of-Systems," Systems Eng., vol. 1, no. 4, pp. 267-284.

McCarter, B. G., and B. E. White. (2009). "Emergence of SOS, sociocognitive aspects." In System of Systems Engineering, Principles and Applications. Jamshidi, M., ed. Boca Raton, FL: CRC Press, pp. 71-105. 
Sage, A.P., and C.D. Cuppan. (2001). “On the Systems Engi- neering and Management of Systems and Federation of Systems," Information, Knowledge, and Systems Management, vol. 2, no. 4, pp. 325-345.

Sage, A.P. (1992).Systems Engineering, N.J: John Wiley.

Sage, A. P. (2003). "Conflict and Risk Management in Complex System of Systems Issues," IEEE Int'l Conf. Systems, Man, and Cybernetics, IEEE CS Press, 5. pp. 3296-3301.

Stevens, R. (2011). Engineering Mega-systems. CRC Press. Boca Raton, FL. 


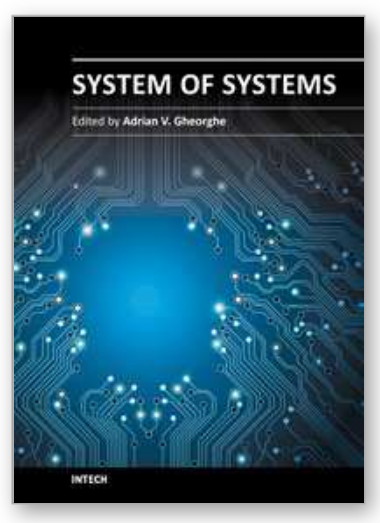

\author{
System of Systems \\ Edited by Dr. Adrian V. Gheorghe
}

ISBN 978-953-51-0101-7

Hard cover, 114 pages

Publisher InTech

Published online 02, March, 2012

Published in print edition March, 2012

The present book proposes and fosters discussion on the current applications in the field of system of systems, with emphasis on the implications of the fact that new developments and area of technical and nontechnical applications are merging. The book aims to establish an effective platform for communication among various types of practitioners and theory developers involved in using the system thinking and systems engineering approaches at the scale of increased complexity and advancing computational solutions to such systems.

\title{
How to reference
}

In order to correctly reference this scholarly work, feel free to copy and paste the following:

G. Reza Djavanshir, Ali Alavizadeh and M.J. Tarokh (2012). From System-of-Systems to Meta-Systems: Ambiguities and Challenges, System of Systems, Dr. Adrian V. Gheorghe (Ed.), ISBN: 978-953-51-0101-7, InTech, Available from: http://www.intechopen.com/books/system-of-systems/from-system-of-systems-tometa-systems-ambiguities-and-challenges

\section{INTECH}

open science | open minds

\section{InTech Europe}

University Campus STeP Ri

Slavka Krautzeka 83/A

51000 Rijeka, Croatia

Phone: +385 (51) 770447

Fax: +385 (51) 686166

www.intechopen.com

\section{InTech China}

Unit 405, Office Block, Hotel Equatorial Shanghai

No.65, Yan An Road (West), Shanghai, 200040, China

中国上海市延安西路 65 号上海国际贵都大饭店办公楼 405 单元

Phone: +86-21-62489820

Fax: +86-21-62489821 
(C) 2012 The Author(s). Licensee IntechOpen. This is an open access article distributed under the terms of the Creative Commons Attribution 3.0 License, which permits unrestricted use, distribution, and reproduction in any medium, provided the original work is properly cited. 